\title{
openheart UK perspective on the changing landscape of non-invasive cardiac testing
}

\author{
Alex Asher (D) , ${ }^{1}$ Rahul Ghelani, ${ }^{1}$ George Thornton, ${ }^{1}$ Krishnaraj Rathod, ${ }^{1}$ \\ Daniel Jones, ${ }^{1,2}$ Andrew Wragg, ${ }^{2,3}$ Adam Timmis ${ }^{2,3}$
}

\begin{abstract}
- Additional material is published online only. To view please visit the journal online (http://dx.doi.org/10.1136/ openhrt-2019-001186).
\end{abstract}

To cite: Asher A, Ghelani $R$, Thornton G, et al. UK perspective on the changing landscape of non-invasive cardiac testing. Open Heart 2019;6:e001186. doi:10.1136/ openhrt-2019-001186

Received 9 0ctober 2019 Revised 7 November 2019 Accepted 18 November 2019

Check for updates

(c) Author(s) (or their employer(s)) 2019. Re-use permitted under CC BY-NC. No commercial re-use. See rights and permissions. Published by BMJ.

${ }^{1}$ Cardiology, Barts Health NHS Trust, London, UK

${ }^{2}$ Faculty of Medicine and Dentistry

, Barts and The London School of Medicine and Dentistry Postgraduate Studies, London, UK

${ }^{3}$ Cardiology, Barts Health NHS Trust, London, UK

Correspondence to Dr Alex Asher; alex.asher@ bartshealth.nhs.uk

\section{ABSTRACT}

Objective To document UK rates of exercise treadmill testing, functional stress testing and CT coronary angiography (CTCA). Specific aims were to determine how rates have changed in the context of changing guideline recommendations within the UK and to identify regional inequalities in the utilisation of testing modalities. Secondary objectives were to compare these trends with national data on revascularisation.

Methods 159 acute National Health Service trusts were served Freedom of Information (FOI) requests to provide total numbers of CTCA and functional imaging tests for each financial year from 2011-2012 to 2016-2017. Results The FOI requests yielded data from $88 \%$ of Trusts, increasing from $81.9 \%$ in $2011-2012 \%$ to $92.1 \%$ in 2016-2017. Exercise treadmill tests (ETTs) were performed by over $97 \%$ of Trusts. ETT was the most commonly performed diagnostic test in the UK across the study period despite declining by $8.4 \%$. Utilisation of noninvasive stress imaging tests increased by $80.9 \%$ during the same period. Myocardial perfusion scintigraphy and stress echocardiography increased by $25.8 \%$ and $73.9 \%$, respectively. The $268 \%$ increase in CTCA scans was yet greater. Trends in test utilisation during the study period showed important regional differences between devolved nations. Comparably, only small changes in rates of invasive coronary angiography and revascularisation have been reported during the study period.

Conclusion Non-invasive imaging in UK Trusts has increased substantially since 2010 with only a small decline in use of the ETT and minimal changes in rates of invasive coronary angiography and revascularisation in the same time period.

\section{INTRODUCTION}

The last 10 years have seen major shifts in UK guideline recommendations for non-invasive cardiac testing of patients with undiagnosed chest pain. Historically exercise treadmill testing (ETT) was recommended as a diagnostic test in patients with suspected coronary artery disease in the UK. ${ }^{1}$ In 2010 the National Institute of Care Excellence (NICE) changed this by recommending that the (ETT) should no longer be used for this purpose due to poor diagnostic accuracy and instead

\section{Key messages}

What is already known about this subject?

- It is not known how utilisation of non-invasive imaging tests and exercise treadmill tests (ETT) have changed in the UK in view of changing recommendations for their use.

What does this study add?

- Utilisation of non-invasive imaging tests rose substantially (81\%) between 2011 and 2017, while use of ETT has reduced only modestly $(8 \%)$. There was no change in audit figures for invasive angiography, percutanoues coronary intervention (PCI) or coronary artery bypass grafting (CABG) in the same period.

How might this impact on clinical practice?

- This study provides an insight into current noninvasive testing utilisation but also identifies areas for improvements in provision and appropriate use of non-invasive imaging tests.

recommended use of non-invasive imaging testing for more accurate diagnosis of coronary artery disease. A further 6 years later in 2016 the guideline was further nuanced with CT coronary angiography (CTCA) becoming the favoured investigation for all patients with new atypical or typical chest pain ${ }^{23}$ and with perfusion and stress imaging preferred for patients with a known diagnosis of coronary artery disease or unsuitable for CTCA. European guidelines for management of chronic coronary syndromes largely mirror these recommendations with an emphasis on use of non-invasive testing prior to revascularisation. $^{4}$

While recommendations for ETT in patients with undiagnosed chest pain are now diminished these tests continue to have an important role for patients with other cardiac disorders. ${ }^{1}$ Equally since the 2010 NICE guideline the scope for use of noninvasive imaging tests has widened beyond just stable coronary artery disease. Cardiac 
CT are important tools in assessing aortic stenosis, masses or congenital heart diseases. Stress echocardiography can be a helpful discriminator in 'low-flow' aortic stenosis. Cardiac MRI or myocardial perfusion scintigraphy (MPS) are used to guide revascularisation decisions using both perfusion and viability assessments.

With expanding indications for these tests, it is not known how their utilisation has changed within the UK in recent years. It is equally unclear how this in turn has impacted rates of invasive coronary angiography (ICA) and revascularisation. These questions are important not only for bench marking purposes but also for identifying efficiency of resources utilisation at a time of increasing constraints. ${ }^{5}$ In the present study we have addressed this knowledge gap by documenting for the first-time rates of non-invasive testing across UK cardiac centres. Specific aims were to determine how rates of testing have changed since 2010 and to identify regional inequalities in the utilisation of testing modalities.

\section{METHODS}

159 acute National Health Service (NHS) trusts and health boards providing adult cardiology services in England, Scotland, Wales and Northern Ireland were identified from each nations NHS website (www.nhs. uk, https://www.scot.nhs.uk, http://online.hscni. net, https://www.wales.nhs.uk). Each trust or health board was asked to provide information under the UK's Freedom of Information (FOI) act 1998. Under the FOI act all public bodies must respond, if feasible within 20 working days, to all requests for information that do not meet exclusions from the act. Each trust was sent five FOI requests via either email or an online request system, requesting that they provide the total numbers of noninvasive cardiac tests, both anatomical (CTCA) and functional (ETT, stress perfusion cardiac MRI, myocardial stress perfusion and stress echocardiography) for each financial year from 2011-2012 to 2016-2017. No information was requested regarding indication for the tests performed due to exclusions of the FOI act precluding this. An individual information request was made for each cardiac investigation and all requests were made within the period of 1 August 2018 to 31 December 2018. Trusts not responding within 20 working days were chased for response via email up to three times before data were presumed to be missing (figure 1). Clarification or rechecking of data was requested from the Trusts using SNOMED codes if incorrect or anomalous data was suspected (ie, data including non-stress cardiac MRI, inconsistency in numbers reported year to year or number of tests reported well above expected levels). The exact FOI requests made for each test can be found in online supplementary file 1. National rates of ICA and revascularisation were obtained from the British Cardiovascular Interventional Society and the Society for Cardiothoracic Surgery registries. ${ }^{6} 7$

This is a descriptive study and no formal statistical analysis has been performed.

Results are displayed as both total number of tests and tests per 100000 of population per year in the UK. Tests are also represented as mean tests per NHS trust per year to account for unreported data from NHS trusts. Data for

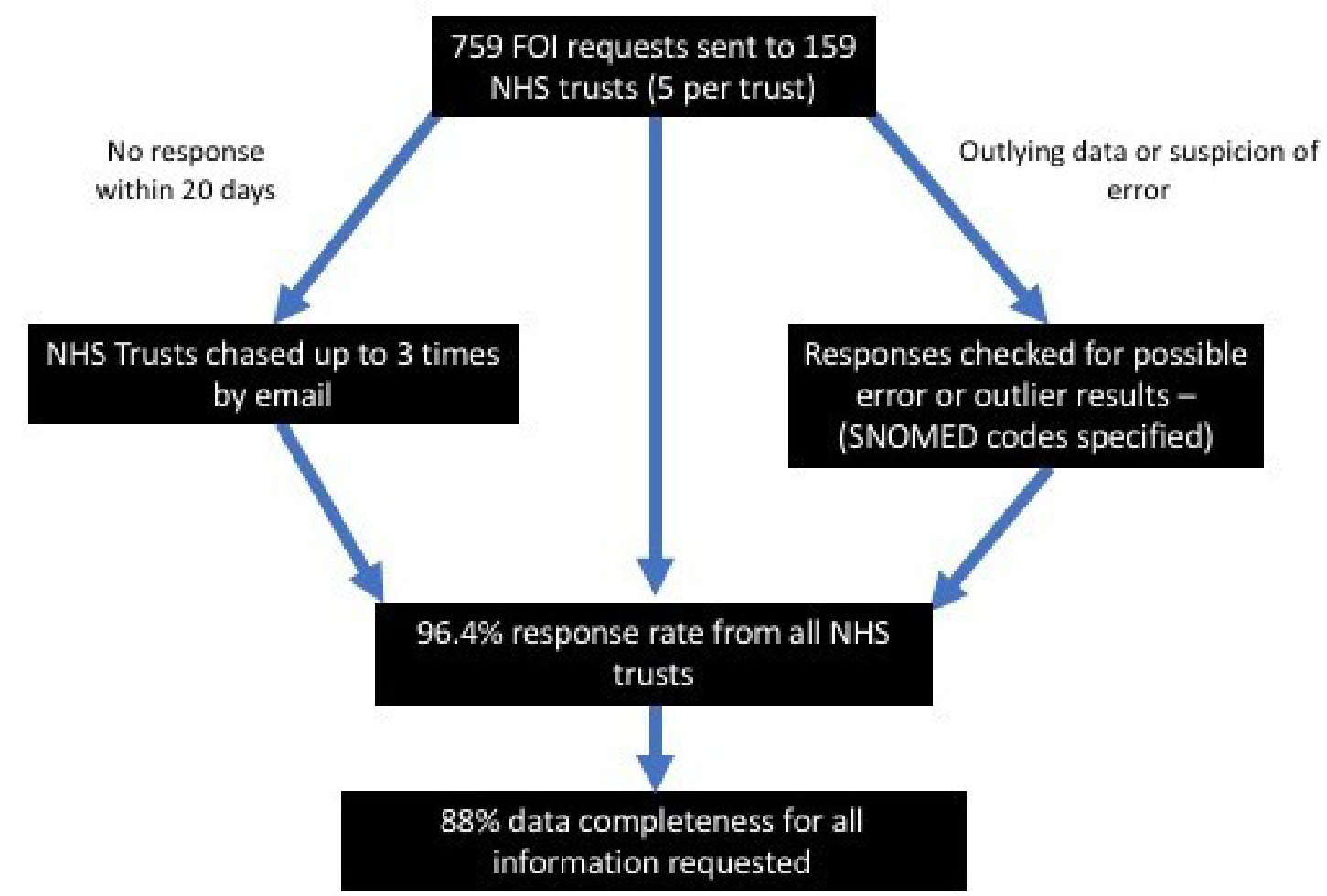

Figure 1 Methods flowchart. FOI, Freedom of Information; NHS, National Health Service. 
Table 1 Total number and percentages of UK National Health Service trusts that responded to Freedom of Information requests performing individual tests between 2011-2012 and 2016-2017

\begin{tabular}{lccccrr}
\hline Test & $\mathbf{2 0 1 1 - 2 0 1 2}$ & $\mathbf{2 0 1 2 - 2 0 1 3}$ & $\mathbf{2 0 1 3 - 2 0 1 4}$ & $\mathbf{2 0 1 4 - 2 0 1 5}$ & $\mathbf{2 0 1 5 - 2 0 1 6}$ & $\mathbf{2 0 1 6 - 2 0 1 7}$ \\
\hline CTCA & $77(56.6 \%)$ & $84(59.2 \%)$ & $100(66.7 \%)$ & $106(70.2 \%)$ & $111(73.5 \%)$ & $116(74.4 \%)$ \\
ETT & $122(97.6 \%)$ & $129(97.0 \%)$ & $132(97.8 \%)$ & $135(97.8 \%)$ & $138(97.9 \%)$ & $141(97.9 \%)$ \\
SE & $73(60.3 \%)$ & $85(65.4 \%)$ & $98(73.1 \%)$ & $102(73.4 \%)$ & $109(76.8 \%)$ & $115(80.4 \%)$ \\
CMR & $27(19.6 \%)$ & $35(24.8 \%)$ & $39(27.3 \%)$ & $40(27.6 \%)$ & $44(30.1 \%)$ & $46(31.5 \%)$ \\
MPS & $79(60.3 \%)$ & $82(61.7 \%)$ & $88(63.3 \%)$ & $89(62.7 \%)$ & $92(64.3 \%)$ & $91(63.6 \%)$ \\
\hline
\end{tabular}

CMR, cardiac stress/perfusion MRI; CTCA, CT coronary angiography; ETT, exercise treadmill testing; MPS, myocardial perfusion scintigraphy; SE, stress echocardiography.

each devolved nation are represented as total numbers and also test per 100000 of the population. Office of National Statistics population data for the UK and devolved nations was used for each successive year from 2011 to 2016 (see online supplementary file 1). Change in test utilisation is represented as a delta from start to end of the period studied.

Regional heat maps were created using GoogleFusion Maps and Keyhole Markup Language files for each NHS sustainability and transformation partnership (STP) or health boards in devolved nations. Tests were normalised to the NHS published populations for each STP footprint in England (2016) and reported populations for each health board in Wales (2009), Scotland (2014) and Northern Ireland (2016). This is represented as tests per 100000 of these populations.

\section{RESULTS}

\section{Data completeness}

A total of 795 FOI requests were made between 1 August 2018 and 30 October 2018. For all diagnostic tests the requests yielded data from $88 \%$ of UK NHS Trusts, the yield increasing from $81.9 \%$ in $2011-2012 \%$ to $92.1 \%$ in 2016-2017 (see online supplementary file 1).

\section{Exercise treadmill test (ETT)}

ETTs were performed by over $97 \%$ of reporting Trusts during the study period (table 1). In 2011-2012 the ETT was the most commonly performed diagnostic test when 136030 (215.3 per 100000 ) were performed across the UK (table 2). Thereafter total numbers declined gradually, as non-invasive imaging tests came to be used more commonly (see figures 2 and 3 and). By 2016-2017 the total number of ETTs performed in the UK had fallen by $8.4 \%$ to 124647 (189.9 tests per $100000,11.8 \%$ decrease), with non-invasive imaging now predominantly used. The data, normalised to those Trusts that supplied ETT information (table 3), showed a similar pattern with a $20.5 \%$ decrease in the mean number of ETTs per reporting Trust.

\section{Non-invasive imaging tests}

Numbers of non-invasive imaging tests increased steeply during the study period, rising by $80.9 \%$ from 130180 in 2011-2012 (206 tests per 100 000) to 235447 in 20162017 (358.7 tests per 100 000). By 2012-2013, numbers had exceeded numbers of ETTs (table 1).

Functional imaging

MPS was offered by $60.3 \%$ of reporting Trusts in 20112012 with little change during the study period (table 1). It was the most commonly utilised functional imaging test with the total number of scans increasing by $25.8 \%$ during the study period, from 69463 in 2011-2012 (109.9 tests per 100000 ) to a peak of 89224 in 2014-2015 (138.1 tests per 100000$)$, declining slightly the next 2 years.

Stress echo imaging was offered by $60.3 \%$ of reporting Trusts in 2011-2012, increasing to $80.4 \%$ in 2016-2017 (table 1). The number of studies in 2011-2012 was 35338 ( 55.9 tests per 100000 ) but utilisation increased by $73.9 \%$ thereafter, peaking at 61458 in 2016-2017 (93.6 tests per 100000 ), only $30 \%$ lower than the number of MPS scans.

\begin{tabular}{|c|c|c|c|c|c|c|}
\hline Test & 2011-2012 & 2012-2013 & 2013-2014 & 2014-2015 & 2015-2016 & 2016-2017 \\
\hline CTCA & 141.7 & 192.9 & 240.9 & 280.8 & 322.1 & 454.7 \\
\hline ETT & 1088.2 & 1007.6 & 1003.1 & 964.6 & 907.7 & 865.6 \\
\hline SE & 292.0 & 322.0 & 349.7 & 374.1 & 402.4 & 429.8 \\
\hline CMR & 44.3 & 56.4 & 72.8 & 82.0 & 94.9 & 107.1 \\
\hline MPS & 530.3 & 573.7 & 636.8 & 628.3 & 613.8 & 611.4 \\
\hline
\end{tabular}

Data are the total numbers of tests performed each year.

CMR, cardiac stress/perfusion MRI; CTCA, CT coronary angiography; ETT, exercise treadmill testing; MPS, myocardial perfusion scintigraphy; SE, stress echocardiography. 


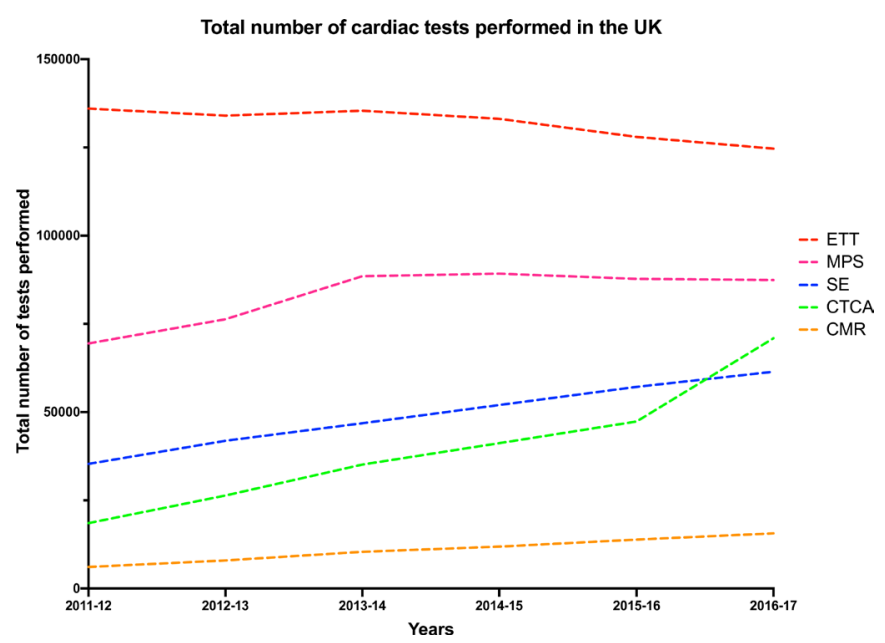

Figure 2 Total number of cardiac tests performed in the UK. CMR, cardiac stress/perfusion MRI; CTCA, CT coronary angiography; ETT, exercise treadmill testing; MPS, myocardial perfusion scintigraphy; SE, stress echocardiography.

Cardiac stress MRI was offered by only $19.6 \%$ of reporting Trusts in 2011-2012, increasing to $31.5 \%$ in 2016-2017 (table 1). The number of scans was consistently lower compared with other imaging tests but increased by $155.9 \%$ during the study period from 6109 (9.7 tests per 100000 ) in 2011-2012 to 15634 (23.8 tests per 100000 ) in 2016-2017. The data normalised to those Trusts that supplied functional imaging information (table 3) confirmed MPS as the most widely used test per Trust and showed similar patterns of increasing imaging activity, most marked for cardiac stress MRI.

\section{CT coronary angiography}

CTCAs were offered by $56.0 \%$ of reporting Trusts in 2011-2012, increasing to $74.4 \%$ in 2016-2017 (table 1). The number of CTCAs totalled 19270 in 2011-2012 (30.5 tests per 100000$)$ but increased by $268 \%$ during the study period, peaking at 70928 in 2016-2017 (108 tests per 100000 ). The data normalised to those Trusts that

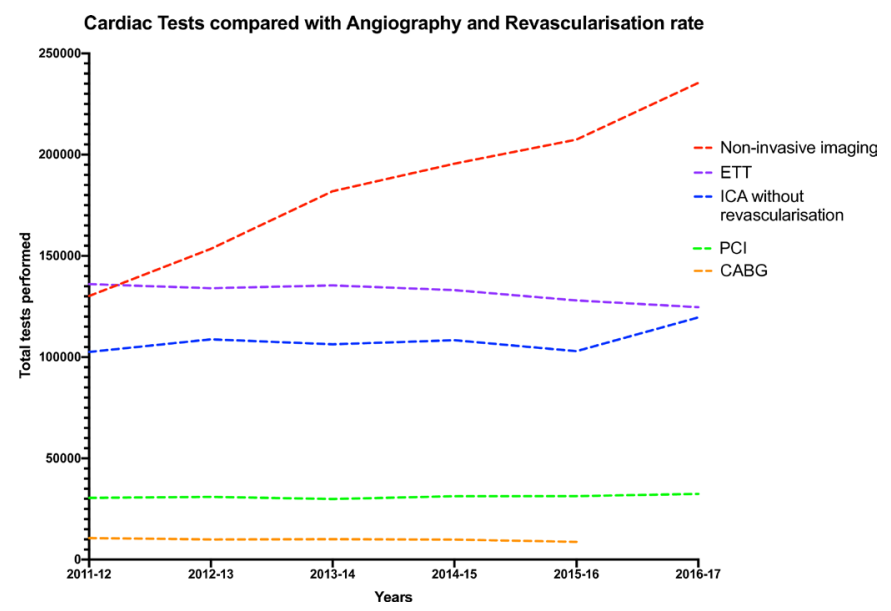

Figure 3 Cardiac Tests compared with Angiography and Revascularisation rate. supplied information (table 3) showed a similar pattern of increasing CTCA activity during the study period.

\section{Regional inequalities in non-invasive test utilisation}

ETT utilisation between 2011-2012 and 2016-2017 declined in English and Welsh Trusts by $15.8 \%$, and $13.5 \%$, respectively, but in Scottish Trusts ETT utilisation increased by $14.1 \%$ and in Northern Ireland Trusts, where ETT per 100000 population far exceeded rates elsewhere in the UK, its utilisation increased by $25.0 \%$ (see figure 3 and online supplementary file 1 ). Noninvasive imaging tests during the same period increased in English, Welsh and Northern Ireland Trusts by $85.1 \%$, $115.7 \%$ and $50.7 \%$ but in Scottish Trusts the increase was only $3.9 \%$ (see figure 3 and online supplementary file 1 ), marking Scotland as the UK state performing the fewest non-invasive imaging tests.

Utilisation of CTCA showed the greatest increase in English and Welsh Trusts (281.4\% and $290.0 \%$ ) but in Scottish and Northern Ireland Trusts increases in CTCA utilisation were more modest $(68.9 \%$ and $45.6 \%)$ and were dwarfed by increases in stress echo utilisation (172.9\% and $291.1 \%)$. Stress cardiac stress/perfusion MRI (CMR) utilisation in all regions was relatively low but showed large increases during the study period (see figure 4 , figure 5 and online supplementary file 1).

\section{Invasive angiography and revascularisation}

National registry data from the British Cardiovascular Interventional Society showed a $7.7 \%$ increase in diagnostic ICA during the study period, numbers increasing from 144506 in 2011 to 155777 in 2016 (figure 2). A similar $6.4 \%$ increase in percutaneous coronary intervention procedures for stable angina occurred during the same period, numbers increasing from 30526 in 2011 to 32475 in 2016. Elective isolated coronary bypass operations recorded in the Society for Cardiothoracic Surgery registry declined by $17.5 \%$ during the study period, from 10671 in 2011 to 8804 in 2015 (most recent available data).

\section{DISCUSSION}

This study reports the utilisation of non-invasive functional and anatomical tests by hospital Trusts across the UK. Temporal trends during a 6-year period from 2011-2012 to 2016-2017 show that utilisation of all noninvasive imaging tests has increased substantially while utilisation of exercise treadmill tests has tended to slowly decline. Trends in test utilisation during the study period showed important regional differences, with Scottish and Northern Irish Trusts reporting little change in utilisation of non-invasive imaging tests.

In the 2010 NICE guideline ETT was no longer recommended to be used to diagnose or exclude stable angina. This recommendation, based largely on the inferior diagnostic performance of the ETT compared with noninvasive imaging tests, ${ }^{8}$ has been validated by investigators who have reported that its diagnostic and prognostic 


\begin{tabular}{|c|c|c|c|c|c|c|}
\hline Cardiac test & 2011-2012 & 2012-2013 & 2013-2014 & 2014-2015 & 2015-2016 & 2016-2017 \\
\hline CTCA-total & 19270 & 27388 & 36132 & 42405 & 48643 & 70928 \\
\hline Per 100000 population & 30.5 & 43.0 & 56.4 & 65.6 & 74.7 & 108.0 \\
\hline SE-total & 35338 & 41861 & 46859 & 51999 & 57146 & 61458 \\
\hline Per 100000 population & 55.9 & 65.7 & 73.1 & 80.5 & 87.8 & 93.6 \\
\hline CMR-total & 6109 & 7948 & 10408 & 11885 & 13857 & 15634 \\
\hline Per 100000 population & 9.7 & 12.5 & 16.2 & 18.4 & 21.3 & 23.8 \\
\hline MPS-total & 69463 & 76301 & 88514 & 89224 & 87776 & 87427 \\
\hline Per 100000 population & 109.9 & 119.8 & 138.1 & 138.1 & 134.8 & 133.2 \\
\hline ETT-total & 136030 & 134012 & 135420 & 133116 & 127986 & 124647 \\
\hline Per 100000 population & 215.3 & 210.4 & 211.2 & 206.1 & 196.6 & 189.9 \\
\hline All non-invasive imaging—total & 130180 & 153498 & 181913 & 195513 & 207422 & 235447 \\
\hline Per 100000 population & 206.0 & 241.0 & 283.8 & 302.7 & 318.6 & 358.7 \\
\hline
\end{tabular}

Data are the mean number of tests performed each year by trusts that responded to the Freedom of Information requests.

CMR, cardiac stress/perfusion MRI; CTCA, CT coronary angiography; ETT, exercise treadmill testing; MPS, myocardial perfusion

scintigraphy; SE, stress echocardiography.

value in patients with suspected angina is limited. ${ }^{9}{ }^{10} \mathrm{In}$ patients with established coronary artery disease, the ETT competes with a range of clinical factors for prognostic assessment and has either not been considered ${ }^{11} 12$ or has failed inclusion ${ }^{13}$ in the development of risk models. This study does not identify indications for non-invasive testing and as such the authors are cautious of drawing firm conclusions on the utilisation of ETT. Certainly, the changes in the 2010 NICE guidelines do not appear to have led to a significant drop in ETT use. Multiple factors are likely responsible for the continuing popularity of the ETT including its low cost, wide availability and status as a test that has been part of cardiological practice for more than 70 years. The superior diagnostic performance and cost-effectiveness of non-invasive imaging tests are well established ${ }^{14}$ and persistently high level of utilisation of ETTs may provide cause for concern if indeed they are being used for assessment of coronary artery disease. This is reflected in the many patients attending chest pain clinics who have a normal ETT but then go on to experience coronary events during follow-up. ${ }^{15}$ Notably trusts with the highest ETT.

The modest decline in the utilisation of ETTs by UK hospital Trusts during the study period was accompanied by a sharp increase in the utilisation of non-invasive imaging tests. By 2012-2013 numbers of non-invasive imaging tests had exceeded numbers of ETTs and the gap in utilisation continued to increase thereafter with MPS the most commonly employed modality. Utilisation of all other non-invasive imaging tests also increased, particularly CTCA, presumably reflecting its introduction as a clinical tool in NICE 2010 guideline recommendation for low risk patients, which has now been extended in the 2016 update. ${ }^{23}$ However, only $74 \%$ of UK Trusts reported utilisation of CTCA in 2016-2017, validating concerns about the implementation of NICE recommendations. ${ }^{1617}$
Regional inequalities in resources appear to remain a challenge with Scotland and Northern Ireland showing only modest increases in CTCA utilisation during the study period despite performing as many if not more scans proportional to population in 2011-2012 compared with England and Wales. By contrast England and Wales have expanded CTCA services more vigorously, by $302 \%$ and $290 \%$, respectively, particularly in South of England and North Wales. However, Wales still lags behind other UK nations in its overall utilisation of CTCA.

The while the increase in utilisation of CTCA is likely to be related in part to NICE 2010 guidelines during the study period it is unclear, however, what effect this guideline has had on the use of functional imaging during the study period. The use of functional imaging often expands beyond use in chest pain clinics and not infrequently in patients with established coronary artery disease, previously revascularised patients or even acute coronary syndromes. What has driven increasing use of these functional tests is not evident from this study. The data does show that, within the functional imaging modalities, use of stress echocardiography and CMR stress perfusion is increasing, while use of MPS remains high but has stalled somewhat in growth. This is reflected in growing number of centres reporting use stress echo and CMR stress compared with a steady state of centres offering MPS.

This study also gives scale and proportion to utilisation of both anatomical (CTCA) and functional imaging in the UK. In 2016-2017, 30\% of all non-invasive tests were CTCA with $70 \%$ being functional imaging. This balance has shifted from the beginning of the study when CTCA contributed just $15 \%$ of all non-invasive tests. Certainly, the high use of functional imaging across UK Trusts during the study period is consistent with the US experience, ${ }^{18-20}$ where concerns have been expressed about 

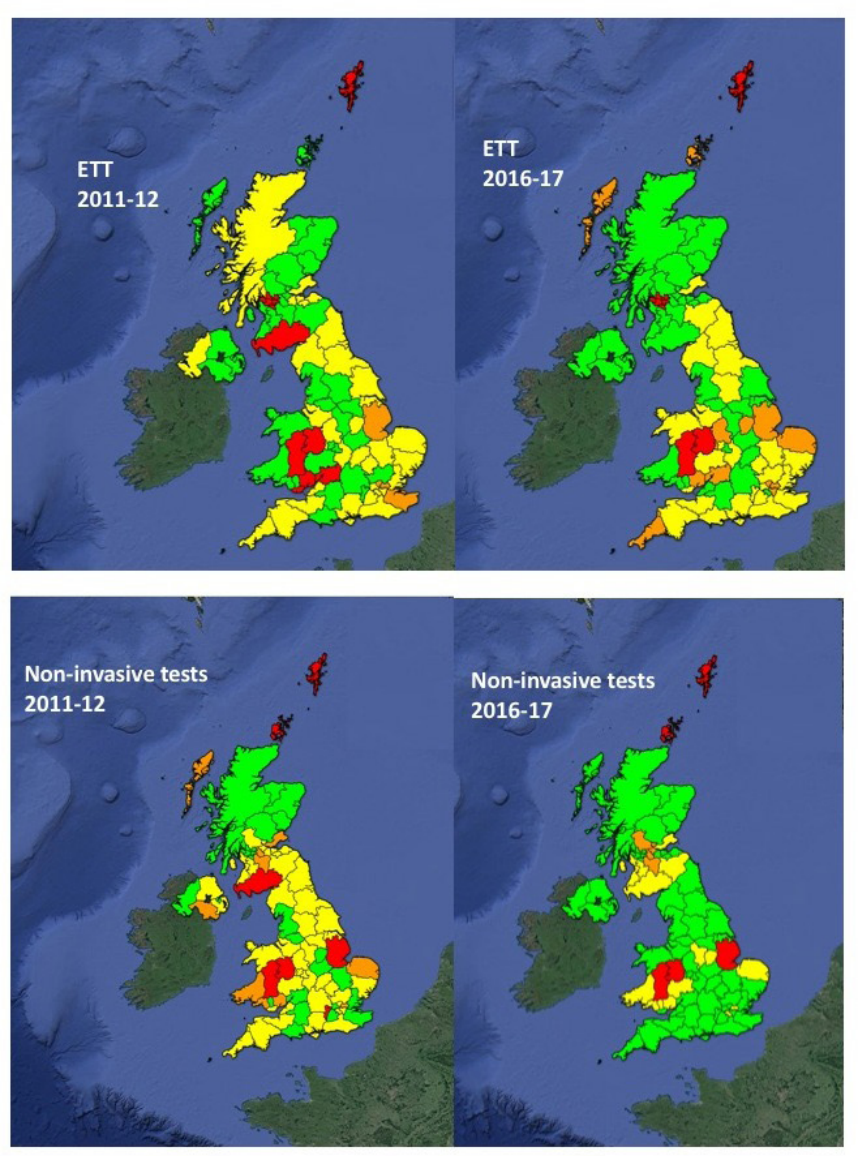

Imaging tests per 100,00 population

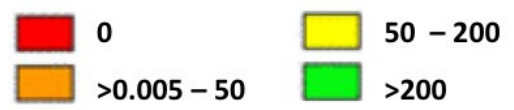

Figure 4 Heat maps demonstrating changes in regional variation in exercise treadmill testing and non-invasive imaging test utilisation in the UK.

inappropriate indications and low diagnostic yield in terms of angiographic coronary artery disease. ${ }^{21-23}$ Importantly there is no evidence that high use of functional testing in US centres has driven improvements in outcomes. ${ }^{24}{ }^{25}$ Conversely the SCOTHEART trial $^{26}$ has recently provided some evidence that anatomical imaging may improve prognosis, although in comparison to ETT testing.

The increase in diagnostic testing that has occurred during the study period has been accompanied with only small changes in numbers of ICA and PCI procedures across the UK. This is a surprising response to the additional 105267 non-invasive tests and in particular $>50000$ additional CTCAs being performed per year that might be expected to have reduced the need for down-stream invasive investigation. Equally conversion rates of ICA to PCI have remained static at around $40 \%$ with no apparent improvement in the diagnostic yield of obstructive coronary disease. There may be multiple explanations for this trend that cannot be described within this dataset alone.
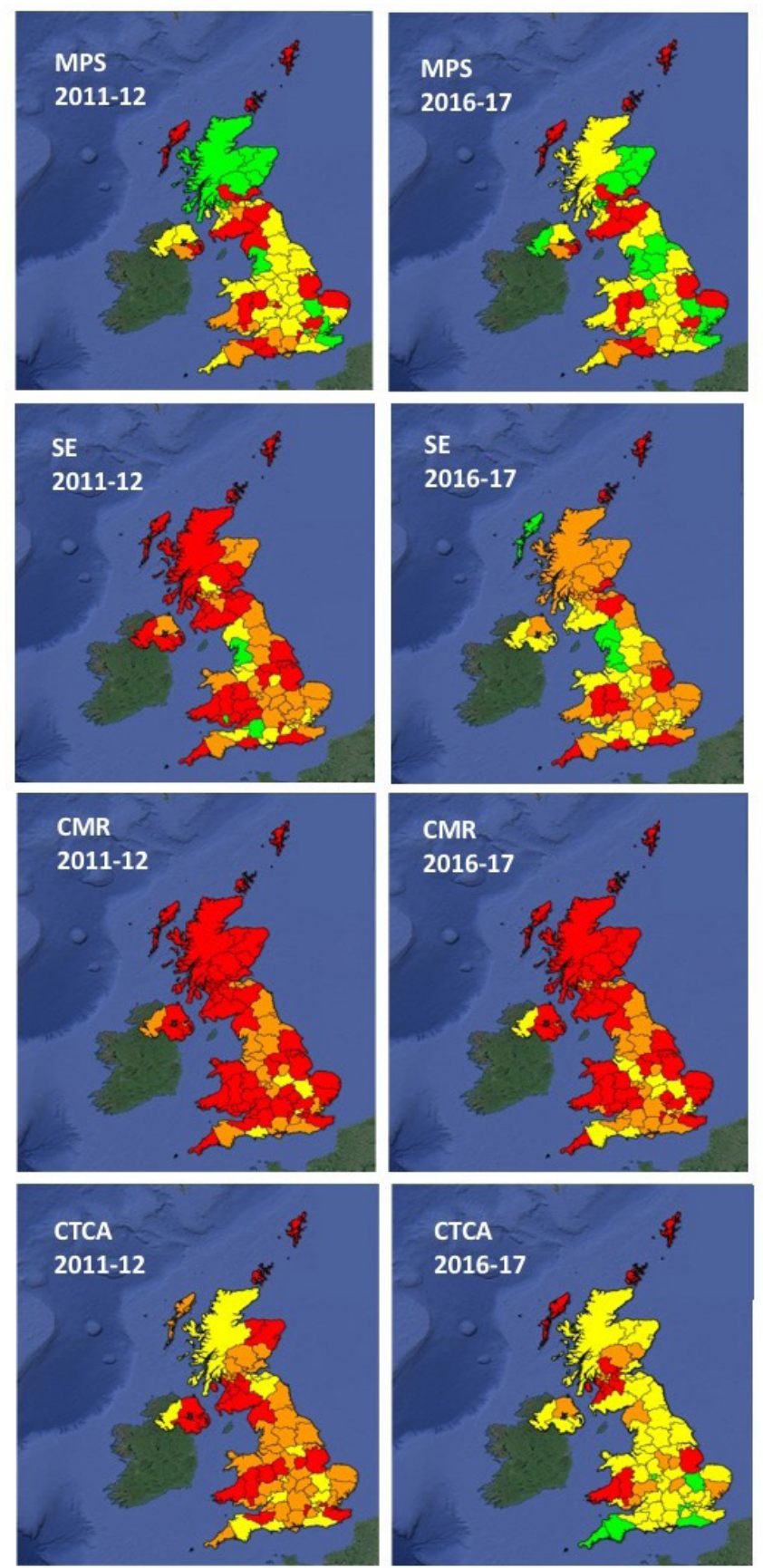

\section{Imaging tests per 100,000 population}
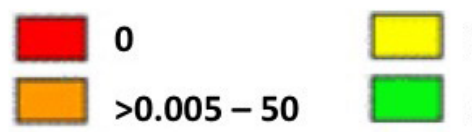

$50-200$

$>\mathbf{2 0 0}$

Figure 5 Heat maps demonstrating changes in regional variation in non-invasive imaging test utilisation in the UK. CMR, cardiac stress/perfusion MRI; CTCA, CT coronary angiography; ETT, exercise treadmill testing; MPS, myocardial perfusion scintigraphy; SE, stress echocardiography.

Two key drivers though are likely to be responsible for this.

First, the individual weakness of each non-invasive test may belie the answer to the static conversion rates 
of ICA to PCI. Sensitivities and specificities of each noninvasive tests vary with CTCA having high specificity but reduced specificity for obstructive $\mathrm{CAD}$, while functional imaging often has good specificity but lacks sensitivity for detecting CAD. This often leads clinicians with a choice of either ordering further tests or referring on for ICA as a final diagnostic test, even if this does not lead to revascularisation. Similar trends have been observed in the USA where increasing rates of invasive management have been recorded due to inappropriate or inaccurate testing. ${ }^{21}$ The 2010 NICE guideline also included the recommendation of ICA for all patients with a risk score $>61 \%$ which may have contributed to greater utility of ICA despite the score overestimating risk of CAD. ${ }^{27}$

Second, increased availability of testing demonstrated by this data does not mean these tests are being utilised appropriately as per guideline recommendations. In fact, the persistently high use of ETT even in 2016-2017 should be seen as a strong indicator that clinicians are quite happy to deviate from guidelines. It could therefore be assumed that the same is being done with regards non-invasive imaging and ICA. No national audit database exists linking non-invasive cardiac testing with downstream management. As such appropriateness of testing is unknown and cost analysis difficult to achieve. This study underlines the importance of prospective national auditing of non-invasive testing in order to achieve the cost savings predicted by NICE. ${ }^{3}$

Although the data reported in this study are novel and nationally relevant three important limitations that need to be acknowledged. First, although the response rate to FOI requests was high it was incomplete with the data yield increasing from $81.9 \%$ in $2011-2012 \%$ to $92.1 \%$ in 2016-2017. The numbers of tests performed across the UK will therefore have been underestimated with some distortion of regional distribution although conclusions about the increasing use of anatomical and functional testing are unaffected. Second, data obtained from the FOI requests is dependent in part on the methods Trusts use in its collection. Most Trusts use coded data for recording diagnostic test utilisation but some extract numbers directly from cardiology or radiology department records. However, it is reassuring that FOI utilisation data for CTCA are very similar to previous 2015-2016 estimates using a different methodology and local validation at the authors centre appears accurate. ${ }^{17}$ Third, the indications or origin of requests for testing were not available for analysis and data from tests is not linked to the British Cardiovascular Intervention Society (BCIS) or the Society for Cardiothoracic Surgery (SCST) registries. As such this limits the conclusions that can be drawn on current practice.

This study has documented for the first time the utilisation of non-invasive testing modalities in Trusts across the UK. Numbers of non-invasive imaging tests have increased substantially with only a small decline in ETTs. The steep increase in utilisation of CTCA may reflect increasing guideline recommendations. Action is now required to reduce regional inequalities and determine appropriateness of cardiac testing in order to take advantage of the diagnostic value and the financial savings predicted by NICE. ${ }^{3}$ The extent to which the increasing rate of imaging in the UK is clinically appropriate requires further review.

Contributors $A A, R G$ and GT collected and analysed the data. AA drafted the manuscript. AW, KR, DJ provided critical analysis and helped re-draft the manuscript. AT edited the final version of the manuscript.

Funding The authors have not declared a specific grant for this research from any funding agency in the public, commercial or not-for-profit sectors.

Map disclaimer The depiction of boundaries on the map(s) in this article do not imply the expression of any opinion whatsoever on the part of BMJ (or any member of its group) concerning the legal status of any country, territory, jurisdiction or area or of its authorities. The map(s) are provided without any warranty of any kind, either express or implied.

Competing interests None declared.

Patient consent for publication Not required.

Provenance and peer review Not commissioned; externally peer reviewed.

Data availability statement Data are available upon reasonable request.

Open access This is an open access article distributed in accordance with the Creative Commons Attribution Non Commercial (CC BY-NC 4.0) license, which permits others to distribute, remix, adapt, build upon this work non-commercially, and license their derivative works on different terms, provided the original work is properly cited, appropriate credit is given, any changes made indicated, and the use is non-commercial. See: http://creativecommons.org/licenses/by-nc/4.0/.

ORCID iD

Alex Asher http://orcid.org/0000-0003-2110-3001

\section{REFERENCES}

1 Recommendation for Clinical Exercise Tolerance Testing. Clinica guidance by consensus. Society for cardiological science and technology and British cardiovascular Society. Available: https:// www.scst.org.uk/pages/page_box_contents.asp?pageid=808

2 Chest pain of recent onset: assessment and diagnosis. Clinical guideline [CG95], 2010. Available: https://www.nice.org.uk/ Guidance/CG95

3 Chest pain of recent onset: assessment and diagnosis. Clinical guideline [CG95], 2016. Available: https://www.nice.org.uk/guidance/ cg95

4 Knuuti J, Wijns W, Saraste A, et al. 2019 ESC guidelines for the diagnosis and management of chronic coronary syndromes. Eur Heart J 2019;100.

5 Walker S, Asaria M, Manca A, et al. Long-Term healthcare use and costs in patients with stable coronary artery disease: a populationbased cohort using linked health records (caliber). Eur Heart J Qual Care Clin Outcomes 2016;2:125-40.

6 BCIS. Audit Results 1991 to present - BCIS. [online], 2019. Available: https://www.bcis.org.uk/resources/audit-results/ [Accessed 30 May 2019].

7 Bluebook.scts.org. SCTS Blue Book Online - Cardiac Surgery Audit Data. [online], 2019. Available: http://www.bluebook.scts.org [Accessed 30 May 2019].

8 Timmis A, Roobottom CA. National Institute for health and care excellence updates the stable chest pain guideline with radical changes to the diagnostic paradigm. Heart 2017;103:982-6.

9 Genders TSS, Steyerberg EW, Hunink MGM, et al. Prediction model to estimate presence of coronary artery disease: retrospective pooled analysis of existing cohorts. BMJ 2012;344:e3485.

10 Sekhri N, Feder GS, Junghans C, et al. Incremental prognostic value of the exercise electrocardiogram in the initial assessment of patients with suspected angina: cohort study. BMJ 2008;337:a2240.

11 Clayton TC, Lubsen J, Pocock SJ, et al. Risk score for predicting death, myocardial infarction, and stroke in patients with stable angina, based on a large randomised trial cohort of patients. BMJ 2005;331.

12 Rapsomaniki E, Shah A, Perel P, et al. Prognostic models for stable coronary artery disease based on electronic health record cohort of 102023 patients. Eur Heart J 2014;35:844-52. 
13 Daly CA, De Stavola B, Sendon JLL, et al. Predicting prognosis in stable angina-results from the Euro heart survey of stable angina: prospective observational study. BMJ 2006;332:262-7.

14 van Waardhuizen CN, Khanji MY, Genders TSS, et al. Comparative cost-effectiveness of non-invasive imaging tests in patients presenting with chronic stable chest pain with suspected coronary artery disease: a systematic review. Eur Heart J Qual Care Clin Outcomes 2016;2:245-60.

15 Sekhri N, Feder GS, Junghans C, et al. How effective are rapid access chest pain clinics? prognosis of incident angina and non-cardiac chest pain in 8762 consecutive patients. Heart 2007:93:458-63.

16 Dreisbach JG, Nicol ED, Roobottom CA, et al. Challenges in delivering computed tomography coronary angiography as the firstline test for stable chest pain. Heart 2018;104:921-7.

17 British Society of Cardiovascular Imaging. The challenge of national CT coronary angiography (CTCA) provision in response to NICE CG95 update, 2016. Available: www.bsci.org.uk/images/Documents/ 2016_BSCI_BSCCT_response_to_NICE_CG95.pdf

18 Ladapo JA, Blecker S, Douglas PS. Physician decision making and trends in the use of cardiac stress testing in the United States: an analysis of repeated cross-sectional data. Ann Intern Med 2014:161:482-90.

19 Ladapo JA, Blecker S, O'Donnell M, et al. Appropriate use of cardiac stress testing with imaging: a systematic review and meta-analysis. PLoS One 2016;11:e0161153.
20 Ladapo JA, Blecker S, Douglas PS. Appropriateness of cardiac stress test use among primary care physicians and cardiologists in the United States. Int J Cardiol 2016;203:584-6.

21 Patel MR, Peterson ED, Dai D, et al. Low diagnostic yield of elective coronary angiography. N Engl J Med 2010;362:886-95.

22 Rozanski A, Gransar H, Hayes SW, et al. Temporal trends in the frequency of inducible myocardial ischemia during cardiac stress testing: 1991 to 2009. J Am Coll Cardiol 2013;61:1054-65.

23 Duvall WL, Rai M, Ahlberg AW, et al. A multi-center assessment of the temporal trends in myocardial perfusion imaging. J Nucl Cardiol 2015;22:539-51.

24 Shah BR, McCoy LA, Federspiel JJ, et al. Use of stress testing and diagnostic catheterization after coronary stenting: association of site-level patterns with patient characteristics and outcomes in 247,052 Medicare beneficiaries. J Am Coll Cardiol 2013;62:439-46.

25 Safavi KC, Li S-X, Dharmarajan K, et al. Hospital variation in the use of noninvasive cardiac imaging and its association with downstream testing, interventions, and outcomes. JAMA Intern Med 2014;174:546-53.

26 Newby DE, Adamson PD, Berry C, et al. Coronary CT angiography and 5-year risk of myocardial infarction. N Engl J Med 2018;379:924-33.

27 Patel MR, Dai D, Hernandez AF, et al. Prevalence and predictors of nonobstructive coronary artery disease identified with coronary angiography in contemporary clinical practice. Am Heart $J$ 2014;167:846-52. 